\title{
Assessment Of Effect Of Neuromuscular Blockade Level On Surgical And Peroperative Conditions During Low Pressure Laparoscopic Cholecystectomy
}

\author{
*Macit YALÇIN, *Ayşe ÖZCAN, *Namık ÖZCAN, *Hülya BAŞAR, *Hatice Dilara \\ ÇOMAK, *Bülent BALTACI
}

Ankara Research and Training Hospital, Anaesthesiology and Reanimation Clinic, Ankara, TURKEY

\section{Background and Goal of Study:} Neuromuscular blockade improves surgical space conditions in laparoscopic cholecystectomy performed during intraabdominal pressures lower than 12 $\mathrm{mmHg}$. Adverse effects like abdominal pain, nausea, vomiting are seen less during low intraabdominal pressures. In the present study, the effects of deep neuromuscular blockade on surgical space conditions in laparoscopic cholecystectomy performed during low intraabdominal pressure were investigated.

Materials and Methods: After the approval of the Instutional Review Board, sixty ASA 1-3 patients with $\mathrm{BMI}<35$, aged 18-65 years old, scheduled for laparoscopic cholecystectomy were enrolled to the study. Patients were randomized into deep (Group $\mathrm{D}, \mathrm{n}=20$ ) and standart neuromuscular groups (Group S, n=20) and control group (Group C, $\mathrm{n}=20)$. Anaesthesia was induced with propofol $2 \mathrm{mg} / \mathrm{kg}$, fentanyl $1 \mu \mathrm{g} / \mathrm{kg}$ and trachea was intubated after rocuronium 0,3 $\mathrm{mg} / \mathrm{kg}$ in all patients. Inhalational anaesthetics were used for maintenance of anaesthesia. Neuromuscular monitoring was performed using TOF-Watch SX acceleromyograph. In group $\mathrm{D}$ additional rocuronium $0,3 \mathrm{mg} / \mathrm{kg}$ was administered after intubation and 0,3-0,6 mg/ $\mathrm{kg}$ to maintain TOF $0, \mathrm{PTC}<1$. In Groups $\mathrm{S}$ and $\mathrm{C}$ additional rocuronium $0,15 \mathrm{mg} / \mathrm{kg}$ was administered if the surgical site was assessed as poor by the surgeon or in case of $25 \%$ recovery in TOF. The surgery was performed at $14 \mathrm{mmHg}$ intraabdominal pressure in Group C, and at $8 \mathrm{mmHg}$ in Groups $\mathrm{S}$ and D. Four point scale and NRS (numeric rating scale) were used to evaluate the surgical space conditions. Pain and nausea-vomiting were assessed postoperatively. Kruskal-Wallis test was used for statistical analysis.

Results: ASA score, BMI, BIS, arterial blood pressure and heart rate values were similar between groups. Surgery was completed at 8 $\mathrm{mmHg}$ intraabdominal pressure in 18 and 5 patients in Groups D and S, respectively. This difference was significant between Groups D and $\mathrm{S}$. There was no difference between Groups $\mathrm{C}$ and D according to NRS and four point scale scores. These scores were significantly high in Group $\mathrm{S}$ compared to Group D $(p<0,05)$.

Discussion: Deep neuromuscular blockade provides better surgical conditions in low pressure laparoscopic cholecystectomy operations compared to standard neuromuscular blockade. Operations can be performed during low intraabdominal pressure by providing deep neuromuscular blockade and the adverse effects of high pressures can be prevented. 